\title{
Immunization: A promising future
}

\author{
Laura Buehning $^{1 *}$ and Isaac Golden ${ }^{2}$ \\ ${ }^{1}$ Researcher, Private Practice in Bioenergetic Medicine, USA \\ ${ }^{2}$ Researcher, Private Practice in Homeopathy, Australia
}

\begin{abstract}
Immunization is an important aspect of global public health. The vaccine industry is presently undergoing rapid expansion and dynamic changes. The public health considerations for the provision of vaccines to the global population is becoming more challenging as a result of this increase in the scope and complexity of vaccines. Seasonal influenza is a significant global public health challenge due to annual seasonal epidemics and occasional pandemics. Vaccination is the cornerstone of influenza prevention and control of epidemics, however vaccine effectiveness is suboptimal with a significant factor being the frequent genetic shift and drift of multiple different virus strains. There is an alternative method for disease-specific immunization known as homeoprophylaxis. Homeoprophylaxis is based on the science of homeopathy. Homeopathy is a comprehensive and holistic therapeutic system that was founded in the late 1700 's and has been used globally for over 200 years. Research supporting the efficacy and effectiveness of homeopathy has increased significantly. Homeopathy is progressively receiving scientific validation and greater acceptance due to the documentation of significant clinical research outcomes as well as the evolving understanding of physics, chemistry, nanoparticles and biomedicine. A recent systematic review of physicochemical research of homeopathic mechanisms revealed multiple publications documenting the physical changes induced by homeopathic medicines. Advances in the fields of systems theory and complex systems biology are also contributing to a greater acceptance and understanding of homeopathy. Bioenergetic medicine is another growing field whose advancing knowledge is supportive of homeopathy. Studies of homeoprophylaxis in multiple different infectious diseases have shown it to be comparably effective to vaccination and without toxicity. This paper discusses the state of research in homeoprophylaxis in both epidemics and as well long-term endemic disease control with a particular emphasis on the prevention and management of influenza-like illnesses.
\end{abstract}

\begin{abstract}
Abbreviations and symbols: WHO: World Health Organization; GVAP: Global Vaccine Action Plan; US: United States; HIV: Human Immunodeficiency Virus; DTP: Diptheria, Tetanus, Pertussis; DNA: Deoxyribonucleic Acid; RCT: Randomized Controlled Trial; NHMRC: National Health and Medical; Research Council (Australia); GE: Genus Epidemicus
\end{abstract}

\section{Introduction}

Immunization is an important aspect of global public health. Established in 1974, the global vaccination program is developed and monitored through the World Health Organization's (WHO) Vaccines and Immunization Programme [1]. The Global Vaccine Action Plan (GVAP) [2] is a policy framework developed by the World Health Assembly in 2012 in order to achieve their vision of the Decade of Vaccines $(2011-2020)$ to provide universal access to immunization [3].

Immunization is considered to be one of the most cost-effective interventions in public health and the GVAP recognizes vaccines as a core component of the human right to health [2]. The vaccine industry is presently undergoing rapid expansion and dynamic changes [4-8]. From the years 2000 to 2008 , the global vaccine market almost tripled, reaching over 17 billion US dollars in global revenue, making the vaccine industry one of the fastest growing economic industries [4]. This growth has continued with the global vaccine market reaching 32 billion US dollars in 2014 and the expectation of over 59 billion by the year 2020 [9]. This increase in the availability of new vaccines has resulted from the development of innovative manufacturing technology, an increase in public-private product development partnerships, and the creation of new funding resources and mechanisms $[4,5]$.
The public health consideration for the provision of vaccines to the global population is becoming more challenging as a result of this increase in the scope and complexity of vaccines [4-8,10,11]. The scope of active immunization has broadened to include vaccines for infectious diseases that require cellular immune responses for effectiveness, such as tuberculosis, malaria, dengue, and HIV, as well as noninfectious conditions such as cancer and autoimmune diseases [4,5,11-14]. Vaccines have also been developed more recently for less virulent pathogens such as varicella, herpes simplex virus and rotavirus [15]. Vaccine development has also become more complex. There are many new ways to formulate vaccines, including gene-based vaccines, virus-like particles, plant-derived vaccines as well as novel adjuvants and delivery systems $[5,7]$. These multifaceted changes are leading to increasingly complex manufacturing and regulatory processes with attendant increases in research, development and production costs $[4,5,7]$. As these new vaccines become available and underutilized vaccines are administered more extensively, the already burdened supply and logistics systems are being further challenged $[4,5,7,10]$. With the continued addition of new vaccines, both the adult and the

*Correspondence to: Laura Buehning, 4015 Carmel View Road \#184, San Diego, CA 92130, USA, Tel: 858-299-9130; E-mail: laurabuehning@gmail.com

Key words: homeopathy, homeoprophylaxis, vaccination, global vaccine action plan, influenza, meningitis, japanese encephalitis, leptospirosis, dengue, public health, childhood endemic diseases, biophysics, physicochemical research, systems theory, nanoparticles, high-dilution pharmacology, bioenergetics, biophotons, electromagnetics

Received: February 04, 2019; Accepted: February 20, 2019; Published: February 25,2019 
pediatric immunization schedules have increased significantly, and this has resulted in the need to administer multiple vaccines simultaneously [16]. The pace of this change has not allowed for adequate postmarketing safety and effectiveness evaluation [16-18]. This has led to a questioning of vaccination schedules and policies by many individuals [16,19-21]. Of significant concern is a 2017 observational study, which showed a 5-fold higher mortality among children receiving the DTP vaccine than in the unvaccinated [16]. They noted that presently there is no prospective study showing a beneficial survival effect of DTP vaccination. This is particularly relevant because DTP is the most widely used vaccine globally [22] and it is used as a performance indicator for national vaccination programs [16].

\section{Influenza}

Seasonal influenza is a significant global public health challenge due to annual seasonal epidemics and occasional pandemics. Each year, approximately 10 to $20 \%$ of the world's population is affected with influenza creating a significant economic and societal burden [23]. This illness is caused by a group of viruses that circulate globally and spread easily from person to person [24]. Worldwide, these annual epidemics are estimated to result in between 3 to 5 million cases of severe illness, and 290,000 to 650,000 deaths per year [25]. The impact of these infections, however, increases significantly with the emergence of more virulent strains of the viruses during pandemics [24]. These pandemics occur because influenza viruses are constantly evolving through genomic mutation and rearrangement [24]. The challenge in managing and preventing these inflections is due to the rapidity in which these viruses can evolve and therefore evade the host's immune system or develop resistance to drug therapy. The evolution of influenza viruses is considered to be due to either antigenic drift or antigenic shift. Antigenic drift is the development of minor changes in the viral genotype within the same viral type whereas antigenic shift is the emergence of novel and potentially pandemic strains due to the rearrangement of viral genomes [24].

The 2017-18 influenza season was particularly severe. High levels of influenza activity began in Australia with reported record-high numbers of laboratory-confirmed influenza cases as well as higher-than-average cases of hospitalization and death [26]. In Europe, the influenza viruses circulated widely with a longer and more severe season than usual [27]. Reports from Europe estimated influenza vaccine effectiveness to be between $25 \%$ and 52\% [25]. The United States also reported a high severity season with elevated numbers of outpatient and emergency visits as well as hospitalizations in broad geographical areas, in all age groups, and over a prolonged period of time [28]. The estimated overall effectiveness of the 2017-18 inactivated influenza vaccine in the United States was 36\% [26]. In Australia, the overall vaccine effectiveness against the presentation to a general practitioner was 33\%, while the effectiveness against hospitalization was only $16 \%$ [29].

Vaccination is the cornerstone of influenza prevention and control of epidemics. Strain-specific vaccines are developed each year with the recommendations of the WHO according to global viral surveillance data from the previous season [26]. Vaccine mismatches with actual circulating strains can result in significantly reduced effectiveness, at times as low as $6 \%[26,30]$. Even in years with good matching between the vaccines and circulating viruses, vaccine effectiveness usually ranges between $40 \%$ and $60 \%(26,30]$. Suboptimal vaccine effectiveness is likely multifactorial with a significant factor being the frequent genetic shift and drift of multiple different virus strains $[26,30]$. This often results in a disparity between the circulating and vaccine virus strains [24].
This has led to efforts to create a universal influenza vaccine that would provide immunological protection again all influenza virus subtypes $[23,26,30]$. Present methodologies being used to address this issue include virus-like particles, T-cell-inducing peptides, recombinant proteins, synthetic viruses, broadly neutralizing antibodies, and nucleic acid and viral vector vaccines $[24,30]$. These novel platforms of vaccine development are currently in early clinical development [24].

\section{Evidence for homeopathy versus conventional medicine}

Our present global immunization program is based on vaccination. As has been discussed, these vaccines are complex biological agents that may include adjuvants, preservatives, genetic engineering, foreign proteins and DNA as well as possible infectious contaminants [7]. Research and development of these biological agents are costly and time-consuming.

There is, however, an alternative method for disease-specific immunization known as homeoprophylaxis. Homeoprophylaxis is based on the science of homeopathy. Homeopathy is a comprehensive and holistic therapeutic system that was founded in the late 1700's and has been used globally for over 200 years [31]. Although homeopathy was a popular form of medicine in the 1800's and up until the early 1900 's [32], it was replaced by pharmaceutical medications with the development of that industry and the reliance on the biochemical paradigm. More recently, homeopathy has seen a resurgence of interest and use with the growth of complementary and alternative medicine [33], especially in Europe, Asia and Latin America [31]. Homeopathy has been integrated into the national health care systems of many of these countries and often the legal standing of homeopathy is equal to that of allopathic medicine [31]. The global use of homeopathy is difficult to assess due to limitations in public health data collection in many high usage countries such as India, however, there are estimates as high as 500 million annually [34]. Even though it is less popular in the United States, the 2012 National Health Interview survey revealed that 5 million adults and 1 million children had used homeopathic treatments in the previous year [32].

Since the development of the biochemical paradigm, homeopathy has been challenged because it does not follow the classical laws of physics and chemistry $[35,36]$. However, there is an increasing body of evidence, both in-vitro and in-vivo, that supports homeopathy to be a viable healing modality [35-41].

Conventional standards for scientific evidence are based on a hierarchy of different research methodologies [33]. Meta-analyses of randomized controlled trials (RCT) are considered to be of the highest import. Next in priority are systemic reviews followed by randomized controlled studies. Of least significance are observational studies, expert opinions, case reports and physiological experiments [33]. Present evidence-based medicine principles require the judicious evaluation of all of these types of clinical evidence $[33,36]$.

Homeopathy is often criticized for not having sufficient evidence from the highest tier of research methodologies, the RCT [35]. However, reviews of commonly used conventional treatments showed that only $23 \%$ had evidence of positive effectiveness based on RCT, while $21 \%$ of treatments had insufficient evidence of any effect [35]. In addition, only $11 \%$ of primary care practices around the world are based on evidence from RCT [35]. Although RCT are considered to be the gold standard, they can by limited by inadequate estimation of effects, methodological flaws, and limited clinical generalizability and applicability (external validity) $[35,38]$ The applicability of the lower tier research modalities 
such as case series and outcome studies, however are usually greater since they have higher external validity and generalizability [36]. Another important issue is the growing awareness of reporting bias by manufacturers and regulatory agencies [42]. Reporting bias has been found to be a widespread phenomenon in the medical literature with attendant overestimation of efficacy and underestimation of safety risks [42]. Finally, the application of these research methodologies developed for the biochemical paradigm is difficult to translate to the homeopathic system of medicine, because it is based on a personalized assessment of multiple clinical factors [38].

Despite these limitations, there is significant research supporting the efficacy and effectiveness of homeopathy [31,35-38,43-46]. The European Committee for Homeopathy and the Central Council for Research in Homoeopathy (India) recently collated research on homeopathy [31]. These two long-standing organizations represent members from more than 70 countries throughout the world [47]. Many physicochemical and pharmacodynamics studies have documented the physiological changes induced by homeopathy medications [31]. Some of the physiological changes demonstrated by homeopathy included changes in apoptosis, histamine levels, protein and mRNA expression, cytokines, prostaglandins, cyclooxygenases, reactive oxygen species, blood glucose, cholesterol levels, insulin activity, and the modulation of gene expression [31]. Statistically significant effects of homeopathy have been reported in meta-analyses, multiple randomized controlled trials, and clinical observational studies [31,36-38]. In addition, homeopathy has a long history of documented positive case studies [38]. Most importantly, cost-effectiveness studies have also frequently shown homeopathy to significantly reduce overall medical costs $[31,37,38]$.

It is important to note that there was a widely publicized negative report against homeopathy by Australia’s National Health and Medical Research Council (NHMRC) [48]. They claimed that there were "no good-quality, well-designed studies with enough participants for a meaningful result that homeopathy caused either greater health improvements than placebo or caused health improvements equal to those of another treatment." The data published by the NHMRC, however, were analyzed by a second research consultant [49]. This analysis did reveal that there were high quality studies showing a positive effect for homeopathy. These results had been eliminated from the initial analysis by the NHMRC because they had applied an arbitrary and unprecedented exclusion criterion of a minimum or 150 participants and a Jadad score of 5 for the inclusion of a study. This exclusion criterion had eliminated the majority of the positive studies that were reported by the Optum Group. The results of the secondary analysis of the effectiveness and quality of the Optum Group study are shown in Table 1.

\section{Biophysics and the mechanisms of homeopathy}

Homeopathy is progressively receiving scientific validation and greater acceptance due to the documentation of significant clinical research outcomes as well as the evolving understanding of physics, chemistry, nanoparticles and biomedicine $[31,50]$. Although there is still much to be determined in regard to the molecular mechanisms of action of homeopathic medicines, there have been significant recent advances in this area [51]. Proposed mechanisms for homeopathy include the "memory" and structuring of solutions as well as the presence of nanostructures in highly dilute solutions [52,53]. Research showing the transmission of biological information into solution, have also suggested a role for electromagnetic fields in this process [52,54,55].

A recent systematic review of physicochemical research of homeopathic mechanisms identified 183 publications since 2003 [56]. Of this research, $48 \%$ were rated as "high quality". The techniques used to demonstrate physicochemical changes induced by homeopathic medicines included electrical impedance, analytical methods, spectroscopy, nuclear magnetic resonance and other imaging techniques, electrochemistry, luminescence, chromatography as well as various physical methods [56]. Of note, the transfer and retention of medicinal properties from highly diluted homeopathic medicines has been demonstrated physically through the induction of structural differences in nuclear magnetic resonance spectra [51].

The determination of pharmacodynamic and biological mechanisms of action of homeopathic medicines has been primarily in the fields of toxicology and immunoallergy [51]. The investigations include assessed mechanisms of action at the molecular, cellular and systemic levels of biological organization [57]. For homeopathic medications in the low to medium dose ranges, the primary mechanistic frameworks are based on hormesis and paradoxical pharmacology $[57,58]$. For highly diluted and dynamized solutions, the proposed mechanisms include sensitivity to bioelectromagnetic signals, the development of water chains for information signaling, and the regulation of bifurcations in systemic networks [57]. High-dilution pharmacology is emerging as a pioneering field in nanomedicine. Nanoparticles possess unique biological and physicochemical properties such as enhanced catalytic reactivity, protein and DNA absorption, bioavailability, as well as electromagnetic and quantum effects that differ from those of macromolecules $[57,59]$ Advancing research in this field is providing credibility to the proposed mechanisms of action of homeopathic medicines [57,59]. Homeopathic medicines have been found to contain nanoparticles, nanoaggregates, and/or nanocrystals of the source compound [59].

Table 1. The effectiveness of homeopathy and the quality of study as shown by optum

\begin{tabular}{|c|c|c|c|c|c|c|}
\hline \multicolumn{7}{|c|}{ Quality Ratings } \\
\hline Result & High & Med & Low & NK & $\#$ & $\%$ \\
\hline Strongly positive & 23 & 9 & 11 & 31 & 74 & 24.8 \\
\hline Tending positive & 14 & 11 & 17 & 36 & 78 & 26.2 \\
\hline Not positive & 38 & 18 & 31 & 48 & 135 & 45.3 \\
\hline Negative & 0 & 0 & 1 & 2 & 3 & 1 \\
\hline Mixed & 2 & 2 & 0 & 4 & 8 & 2.7 \\
\hline Total & 77 & 40 & 60 & 121 & 298 & \\
\hline Percentage & 25.8 & 13.4 & 20.1 & 40.6 & 100 & 100 \\
\hline
\end{tabular}

Abbreviations: NK: Not Known; \#: Number; \%: Percentage

Quality ratings:

High - High Jadad score 4,5; Other measures $>75 \%$

Med - Medium Jadad score 3; Other measures $45-74 \%$

Low - Low Jadad score 1,2; Other measures 1-44\% 
Advances in the fields of systems theory and complex systems biology are also contributing to a greater acceptance and understanding of homeopathy [57]. Homeopathy is based on a holistic and dynamic view of health and disease, which includes the concepts of systems biology such as nonlinearity, chaos, emergence, and adaptation [57]. The expanding understanding of complex networks has revealed them to be extremely sensitive to minor perturbations as is induced with a homeopathic medicine [57]. The ultimate expression of an input into a complex system is dependent upon a multiplicity of elements acting synergistically, antagonistically and through various feedback loops [57].

Bioenergetic medicine is another growing field whose advancing knowledge is supportive of homeopathy [60-65]. This field is particularly important because it evaluates long-range forms of communication, which transcend the inter-molecular level to the supramolecular levels of organization of biological systems [57]. Many molecular systems have demonstrated sensitivity to electromagnetic fields [55]. Some examples include photoreceptors, chlorophyll, heat shock proteins, membrane ionic channels as well as others [57]. In addition, living systems themselves generate multiple electromagnetic fields such as membrane polarization/depolarization, the mitochondrial electrontransport chain, muscle contraction, piezoelectric activity and the release of biophotons by DNA, to name a few [57]. Biophoton emission at a low intensity is virtually universal to all living organisms [57]. Biophotons are believed to be important for long-range forms of communication enabling the synchronous and coherent integration of biological processes [57]. DNA has been found to be the main source of biophotons in living cells and these emissions are hypothesized to be particularly important in the transmission of DNA information. These biophotons have been identified in highly potentized homeopathic remedies by delayed luminescence [66]. This technique was even able to determine the source and potency of the homeopathic preparation [66]. It is hypothesized that biophotons influence and regulate the coherent biological field and therefore assist in regulating enzymatic activity and other biological systems [67].

\section{Homeoprophylaxis}

Homeopathic medications have been used as a method of preventive immunotherapy for over 200 years [68-70]. This method for infectious disease-specific immunization is known as homeoprophylaxis. The intent of homeoprophylaxis is to educate the immune system in order to reduce the incidence of infectious and chronic diseases [71]. It has been utilized for the management of both epidemic and endemic contagious diseases [69]. Homeopathy became popular in both the United States and Europe during the 19th century as a result of its success in treating several epidemics, including typhus, cholera, yellow fever, and scarlet fever [72].

Observational studies of homeoprophylaxis have shown it to be comparably effective to vaccination and without toxicity [73]. Toxicity is eliminated with homeopathic remedies because they do not require adjuvants or preservatives and they do not contain any pathogenic material. One common method of homeopathic infectious disease prevention involves the use of "nosodes" [69]. These homeopathic medications are made from highly diluted and potentized disease products to elicit an immune response. The second method requires the identification of a homeopathic remedy, which induces symptoms similar to the disease and is frequently used to treat that infection. This remedy is known as the Genus Epidemicus (GE) [69].
Short-term homeoprophylaxis is the use of homeopathic medicines to provide immunological protection during epidemics. Recent publications of large-scale epidemiological studies of shortterm homeoprophylaxis have shown very promising results (ranging from $66 \%$ to $99 \%$ effectiveness) for bacteria, viruses, and spirochetes, surpassing the effectiveness of many vaccines [73]. Some of the most prominent studies will be highlighted.

The first study presented in this review is an outbreak of meningococcal meningitis, which occurred in the city of Blumenau, Brazil in 1998 [74]. Meningococcal meningitis is a severe bacterial meningitis with significant mortality and morbidity worldwide. There are several different serotypes of this disease and an effective vaccine for serogroup B was only recently developed. The outbreak did not qualify according to the Brazilian Health Department for the initiation of a vaccination campaign. Therefore, a program of homeoprophylaxis using the disease nosode Meningococcinum was developed instead. This homeopathic medication was administered voluntarily to the population age 0 to 20 over three days at the public health clinics. The homeoprophylaxis was administered to 65,826 people and an estimated 23,539 persons could not be reached to receive the immunization. This program provided a statistically significant $95 \%$ protection from this severe bacterial infection after 6 months and $91 \%$ after 12 months. A similar program of homeoprophylaxis with Meningococcinum for meningococcal meningitis was performed in Sao Paulo Brazil in 1974 [75]. In this case 18,640 people were immunized and 6,340 could not be covered. This study showed $95 \%$ effectiveness over the 6 months of the study. Additional public health programs in Sao Paulo Brazil in 2001 and 2006 resulted in dramatic reductions in the incidence of meningitis [72].

Impressive results were also obtained with Japanese Encephalitis, which is one of the most important types of viral encephalitis globally and has been endemo-epidemic in India since the1990s. Between 1993 and 1999, 5308 cases were recorded in the state of Andhra Pradesh, India with 1511 fatalities. A vaccination program was not developed at that time due to vaccine cost and availability. In 1999, a homeoprophylaxis program using Genus Epidemicus, miasmic and constitutional remedies was developed [76]. Homeopathic prophylactic medicines were administered annually in endemic regions of this state by the government primary health centers to children up the age 15. Approximately 20 million children were treated. This program resulted in significant reductions in both mortality and morbidity and a sequential reduction of annual cases with the elimination of all cases by 2003 . A recent analysis of this data has confirmed the use of large homeoprophylaxis interventions against a range of diseases including Japanese Encephalitis in three countries, usually directed by government agencies and undertaken by doctors employed by these agencies [77]. The use in over 250 million people on an annualized basis was identified.

Leptospirosis is a potentially serious disease caused by infection with a Gram-negative bacterium Leptospira. It is a severe health problem in developing countries and is endemic in Cuba with peaks in the hurricane season. Vaccination with vaxSpiral, a 3-valent leptospirosis inactivated vaccine, is provided annually in Cuba but significant epidemics still occur despite vaccination. In 2007 and 2008, Cuban health officials conducted a large homeoprophylaxis intervention in three regions of the country that had received extensive hurricane damage and were therefore more susceptible to leptospirosis epidemics [78-80]. A nosode, nosoLEP was prepared from 4 strains of inactivated leptospiras. Homeoprophylaxis was administered instead of 
vaccination to 2.3 million people in these regions with large reductions in disease incidence and control of the epidemic.

Impressive results in the application of homeoprophylaxis for the control of Dengue fever have also been reported. Dengue is an acute, febrile disease caused by a virus of the Flaviviridae family. It is the most significant arbovirosis with significant economic and social impacts and an estimated 50 to 100 million cases each year in more than 100 countries [72]. In 2007, a "Homeopathy Campaign" was instituted in Brazil using a homeopathic complex of three GE remedies to 156,000 asymptomatic and 129 symptomatic patients [72]. The disease incidence fell by $93 \%$ in the region where the program was used whereas the disease incidence increased by $128 \%$ in the regions without the program. A similar program in Brazil in 2001 resulted in a $81.5 \%$ decrease in Dengue incidence which was highly significant as compared with regions that did not receive the homeopathic prophylaxis $(\mathrm{P}<0.0001)$ [81]. A Dengue treatment program was also instituted in Cuba in 2009 using GE remedies [73]. Homeoprophylaxis was given to around 20,000 residents with an effectiveness of $74.1 \%$ and $100 \%$ in two different survey periods. In addition, there have been multiple reports of successful Dengue public health homeoprophylaxis programs in India [82-83].

These successes have increased global interest in homeoprophylaxis as a more rapid and cost-effective means of infectious disease control than vaccines during epidemics [74,78].

Long-term homeoprophylaxis is the regular but infrequent (annual) administration of homeopathic medications to provide long-lasting immunological protection against childhood endemic infectious diseases. This application of homeoprophylaxis is much more difficult to study because of the duration of treatment and follow up necessary as well as the ethical considerations of parents choosing not to give standard vaccinations to their children for these diseases. Despite these limitations, long-term homeoprophylaxis was clinically studied as an alternative to the recommended immunization schedule for infants and children in a cohort of 1,200 patients from 1986 until 2003 [84-86]. This observational study used patient surveys to assess the effectiveness of homeoprophylaxis over this time period. Homeopathic preparations for 7 diseases (pertussis, polio, haemophilus influenzae, diphtheria, tetanus, measles, and mumps) were administered to children in the survey. Surveys addressing the effectiveness and side effects of the program as well as the incidence of other common childhood illnesses were collected from 1986 to 2003.

The long-term effectiveness of the program was determined by the incidence of a clinical infection with one of the seven diseases among those children whose parents confirmed that they were definitely exposured to that disease after receiving the relevant prophylactic. All children whose parents did not believe that they were exposed to a targeted infectious disease were excluded and the disease incidence was calculated only in exposed children. The rates of infection were compared to national attack rates for the relevant diseases enabling an effectiveness figure to be calculated.

Although it was a relatively small observational study, homeoprophylaxis showed $90 \%$ effectiveness in seven different childhood illnesses (pertussis, polio, haemophilus influenza, diphtheria, tetanus, measles, and mumps) and it was the most effective method of the 4 methods studied. These results open the possibility that homeoprophylaxis could provide comparable effectiveness to many vaccines. In addition, this study showed that patients treated with homeoprophylaxis experienced improved long-term health outcomes when compared to conventional vaccination $[84,86]$.

\section{Homeopathy and influenza}

As was previously discussed, our present methods for the treatment and prevention of influenza are less than adequate. Homeopathy has a long history of the management and prevention of these infections and even in the United States, they are in the top ten nonprescription products used for coughs, colds, and flu [88]. A systematic review was performed by the Cochrane Library of the use of a particular homeopathic medicine, Oscillococcinum, in the prevention and treatment of influenza [89]. This showed that Oscillococcinum was effective in reducing symptoms but not in preventing the illness. This review was limited by the inclusion of only small randomized placebo-controlled trials with small sample sizes and therefore low power, as well as the fact that only one of many potential homeopathic medicines was studied.

Internationally, there have been some larger multi-center prospective observational clinical studies comparing the homeopathic management of influenza-like illnesses to conventional allopathic therapy [90,91]. These studies showed an equal effectiveness of the two treatments; however homeopathy had a more rapid onset of improvement and fewer side effects than conventional therapy. A prospective observational multicenter study of the outpatient management of influenza-like illnesses in 8 regions in France also showed homeopathic treatment to be equal to allopathic treatment [88].

Homeoprophylaxis for the prevention of influenza-like illnesses has also been studied. It was shown to be effective in children in a blind randomized, placebo-controlled trial from Brazil [92]. The homeopathic medications used were either a homeopathic biotherapy prepared from intact influenza A virus or a homeopathic complex frequently used in that region for influenza. This study showed a statistically significant reduction of influenza episodes in children receiving either of the two homeopathic treatments versus placebo. Another retrospective cohort study looking at the prophylactic use of the homeopathic medicine Influenzinum, however, did not show a protective effect [93]. The less rigorous methodology of this study as well as the use of a less specific homeopathic medicine could account for the lack of effectiveness.

There are two small studies comparing homeoprophylaxis to vaccination for influenza. A prospective observational study of 150 participants compared regular vaccination (Vaxigrip), a combination homeopathic medicine, or no immunization [94]. In this study, the vaccinated cohort was most likely to acquire influenza-like infection and experienced significantly more adverse reactions. Another randomized double-blind prospective study of 30 participants compared standard vaccination to Influenzinum homeopathic medicine for 13 weeks [95]. This study found equal efficacy of the two methods in the prevention of influenza, however the vaccination cohort experienced greater adverse reactions.

In addition, preliminary observational results are available from a public health intervention against the Swine Flu conducted in Cuba [96]. In 2010, the Cuban government directed the Finlay Institute to homeopathically immunize the entire population over 12 months of age against Swine Flu. This program involved over 9.8 million people and also included immunization against pneumococcal disease. In the year of the intervention, there were only a few hundred reported cases and only 12 recorded deaths from Swine Flu nationally. For pneumococcal disease, annual records showed an over $20 \%$ reduction in cases in the year of the intervention. 


\section{The future of immunization}

These studies show highly promising results for the use of homeoprophylaxis in the management of public health infectious diseases. In these studies, which include bacteria, viruses and spirochetes, the effectiveness of homeoprophylaxis is equal to or better than vaccination. Homeoprophylaxis has the advantages of low cost and rapid development, ease of distribution and administration, coverage of multiple organism strains, and minimal side effects.

Given the importance and extent of our global immunization program, it would seem prudent, given the results outlined in this paper, that greater attention in terms of research and public health applications be applied to homeoprophylaxis in the future. It could contribute significantly to creating a positive future of infectious disease prevention and management.

\section{Authorship and contributorship}

This paper is the original work of the authors.

Both authors have made significant contributions to the paper and have read and approved the final manuscript.

This work has not been submitted for publication elsewhere.

\section{Acknowledgements}

None.

\section{Funding information}

Laura Buehning MD MPH received a grant of $\$ 2,500$ from Osteopathy's Promise to Children, a nonprofit organization in San Diego California. This grant was to assist with the costs of the preparation of this manuscript and the presentation of this information at professional meetings.

\section{Competing interests}

None.

\section{References}

1. Bustreo F, Okwo-Bele JM, Kamar L (2015) World Health Organization perspectives on the contribution of the Global Alliance for Vaccines and of Immunization on reducing child mortality. Arch Dis Child 100(Suppl 1): s34-37. [Crossref]

2. WHO-Global Vaccine Action Plan. [online] Available at: https://www.who.int/ immunization/global_vaccine_action_plan/en/. [Accessed 2/11/19].

3. Cherian T, Okwo-Bele JM (2014) The decade of vaccines global vaccine action plan: shaping immunization programmes in the current decade. Expert Rev Vaccines 13: 573575. [Crossref]

4. WHO, UNICEF, World Bank (2009) State of the world's vaccines and immunization. [online] 3rd ed. Geneva, World Health Organization. Available at: https://www.who.int/ immunization/sowvi/en/ [Accessed 2/12/19].

5. Rappuoli R, Black S, Lambert PH (2011) Vaccine discovery and translation of new vaccine technology. Lancet 378: 360-368. [Crossref]

6. Koslap-Petraco MB, Judelsohn RG (2008) Societal impact of combination vaccines: Experiences of physicians, nurses, and parents. J Pediatr Health Care 22: 300-309. [Crossref]

7. Ulmer JB, Valley U, Rappuoli R (2006) Vaccine manufacturing: challenges and solutions. Nat Biotechnol 24: 1377-1383. [Crossref]

8. Ward BJ (2000) Vaccine adverse events in the new millennium: Is there reason for concern? Bull World Health Organ 78: 205-215. [Crossref]

9. The Statistics Portal (nd) Global vaccine market revenues from 2014 to 2020 . The Statistics Portal. [online] Available at: https:/www.statista.com/statistics/265102/ revenues-in-the-global-vaccine-market/ [Accessed 2/12/19].
10. Levine OS, Bloom DE, Cherian T, de Quadros C, Sow S, et al. (2011) The future of immunisation policy, implementation, and financing. Lancet 378: 439-448. [Crossref]

11. Moxon ER, Siegrist CA (2011) The next decade of vaccines: Societal and scientific challenges. Lancet 378: 348-359. [Crossref]

12. Papaioannou NE, Beniata OV, Vitsos P, Tsitsilonis O, Samara P (2016) Harnessing the immune system to improve cancer therapy. Ann Transl Med 4: 261. [Crossref]

13. Moxon ER, Das P, Greenwood B, Heymann DL, Horton R, et al. (2011) A call to action for the new decade of vaccines. Lancet 378: 298-302. [Crossref]

14. Chen RT, DeStefano F (1998) Vaccine adverse events: Causal or coincidental? Lancet 351: 611-612. [Crossref]

15. O'Leary ST, Parashar UD, Crane LA, Allison MA, Stokley S, et al. (2013) Adoption of rotavirus vaccine by U.S. physicians: Progress and challenges. Am J Prev Med 44: 56-62. [Crossref]

16. Mogensen SW, Andersen A, Rodrigues A, Benn CS, Aaby P (2017) The introduction of diphtheria-tetanus-pertussis and oral polio vaccine among young infants in an urban African community: A natural experiment. EBioMedicine 17:192-198. [Crossref]

17. Weinberg GA, Szilagyi PG (2010) Vaccine epidemiology: efficacy, effectiveness, and the translational research roadmap. J Inf Des 201: 1607-1610. [Crossref]

18. Verricchio F, Iskander J, Destefano F, Ball R, Pless R, et al. (2004) Understanding vaccine safety information from the Vaccine Adverse Event Reporting System. Pediatr Infect Dis J 23:287-294. [Crossref]

19. Miller NZ (2016) Combining childhood vaccines at one visit is not safe. JP\&S 21 47-49.

20. Scherer LD, Shaffer VA, Patel N, Zikmund-Fisher BJ (2016) Can the vaccine adverse event reporting system be used to increase vaccine acceptance and trust. Vaccine 34 : 2424-2429. [Crossref]

21. Betsch C, Sachse K (2012) Debunking vaccination myths: strong risk negations can increase perceived vaccination risks. Health Psychol 32:146-155. [Crossref]

22. Vander Ende K, Gacic-Dobo M, Diallo MS, Conklin LM, Wallace AS (2018) Global Routine Vaccination Coverage - 2017. MMWR Morb Mortal Wkly Rep 67: 1261-1264. [Crossref]

23. Peasah SK, Azziz-Baumgartner E, Breese J, Meltzer MI, et al. (2013) Influenza cost and cost-effectiveness studies globally-a review. Vaccine 31: 5339-5348. [Crossef]

24. Kumar A, Meldgaard TS, Bertholet S (2018) Novel Platforms for the Development of a Universal Influenza Vaccine. Front Immunol 9: 600. [Crossref]

25. WHO (2018) Influenza Fact Sheet [online] Available at: http://www.who.int/ mediacentre/factsheets/fs211/en [Accessed 8/80/2018].

26. Paules CI, Sullivan SG, Subbarao K, Fauci AS (2018) Chasing Seasonal Influenza - The Need for a Universal Influenza Vaccine. $N$ Engl J Med 378: 7-9. [Crossref]

27. ECDPC (2018) Weekly influenza update, week 20, May 2018. [online] Available at: https://ecdc.europa.eu/en/publications-data/weekly-influenza-update-week-20may-2018. [Accessed 8/30/2018].

28. Blanton L, Alabi N, Mustaquim D, Taylor C, Kniss K, et al. (2018) Update: Influenza activity in the United States during the 2017-28 season and composition of the 2018-19 influenza vaccine. MMWR Morb Mortal Wkly Rep 76: 634-642.

29. Australian Department of Public Health (2017) 2017 influenza season in Australia: a summary from the National Influenza Surveillance Committee [online] Available at http://www.health.gov.au/internet/main/publishing.nsf/Content/097F15A91C05FBE7 CA2581E20017F09E/\$File/2017-season-summary-22112017.pdf. [Accessed 2/12/19].

30. Rajão DS, Pérez DR (2018) Universal Vaccines and Vaccine Platforms to Protect against Influenza Viruses in Humans and Agriculture. Front Microbiol 9: 123. [Crossref]

31. Liga Medicorum Homoeopathica Internationalis (2015). Scientific framework of homeopathy: evidence-based homeopathy. 69th LMHI Congress. Paris, France.

32. Podolsky SH, Kesselheim AS (2016) Regulating Homeopathic Products - A Century of Dilute Interest. $N$ Engl J Med 374: 201-203. [Crossref]

33. Institute of Medicine (2005) Complementary and alternative medicine in the United States. Washington, DC. The National Academies Press.

34. Bodeker G, Ong CK, Grundy C, Burford G, Shein K, et al. (2005) WHO global atlas of traditional, complementary and alternative medicine. WHO Centre for Health Development, Kobe, Japan. Available at: http://it-book.org/pdf/who-global-atlas. [Accessed 2/12/19]. 
35. Merizalde BA (2016) The evidence for homeopathy. Int J Complement Alt Med 3: 00086.

36. Reilly D, Taylor MA, Beattie NG, Campbell JH, McSharry C, et al. (1994) Is evidence for homoeopathy reproducible? Lancet 344: 1601-1606. [Crossref]

37. Baumgartner S, Behnke J, Frie-Erb M, Kosters C, et al. (2016) The current state of homeopathic research. Kothen Scientific Society for Homeopathy [online] Available at: https://www.researchgate.net/publication/314094972. [Accessed 2/12/19].

38. Van Wassenhoven M (2005) Priorities and methods for developing the evidence profile of homeopathy. Recommendations of the ECH General Assembly and XVIII Symposium of GIRI. Homeopathy 94:107-124. [Crossref]

39. HRI Research (nd) Homeopathy Research Institute. [online] Available at: https:// www.hri-research.org/hri-research/learning-more-from-existing-evidence/systematicreview-programme/. [Accessed 2/11/19].

40. Research Library (nd) National Center for Homeopathy [online] Available at: https:// www.homeopathycenter.org/research. [Accessed 2/11/19].

41. Homeopathic Research Database. (nd) Initiative to Promote Research in Homeopathy [online] Available at: http://researchinhomeopathy.org/database/. [Accessed 2/11/19].

42. McGauran, N, Wieseler, B, Kreis J, Schuler YV, Kölsch H, et al. (2010) Reporting bias in medical research - a narrative review. Trials 11:37. [Crossref]

43. Bellavite P, Marzotto M, Chirumbolo S, Conforti A (2011) Advances in homeopathy and immunology: a review of clinical research. Front Biosci (Schol Ed) 3: 1363-1389. [Crossref]

44. Witt C, Keil T, Salim D, Roll S, Vance W, et al. (2005) Outcome and costs of homoeopathic and conventional treatment strategies: a comparative cohort study in patients with chronic disorders. Complement Ther Med 13: 79-86. [Crossref]

45. Spence DS, Thompson EA, Barron SJ (2005) Homeopathic treatment for chronic disease. A 6-year university-hospital outpatient observational study. J Altern Complement Med 11: 793-798. [Crossref]

46. Linde K, Clausins N, Ramirez G, Melchart D, Eitel F, et al. (1997) Are the clinical effects of homeopathy all placebo effects? A meta-analysis of randomized, placebocontrolled trials. Lancet 350: 834-843. [Crossref]

47. Cope G (2016) International educational standards for homeoprophylaxis. Homoeopathic Links 29: 113-116.

48. Optum (2013) Effectiveness of homeopathy for clinical conditions: Evaluation of the evidence [online] Available at https://www.hri-research.org/wp-content/ uploads/2014/07/Homeopathy-Overview-Report.pdf. [Accessed 2/12/19].

49. Golden I (2015) Response to the final NH\&MRC report in March 2015. Similia 27: 5-8.

50. Becker-Witt C, Weisshuhn TE, Lüdtke R, Willich SN (2003) Quality assessment of physical research in homeopathy. J Altern Complement Med 9: 113-132. [Crossref]

51. Khuda-Bukhsh AR (2003) Towards understanding molecular mechanisms of action of homeopathic drugs: an overview. Mol Cell Biochem 253: 339-345. [Crossref]

52. Muehsam DJ (2018) Healing waters? Commentary on two experimental studies and a review of homeopathy research. J Altern Complement Med 24: 407-408. [Crossref]

53. Bellavite P, Marzotto M, Olosso D, Moratti E, Conforti A, et al. (2014a) High-dilution effects revisited. 1. Physicochemical aspects. Homeopathy 103: 4-21. [Crossref]

54. Montagnier L, Del Giudice E, Aïssa J, Lavallee C, Motschwiller S, et al. (2015) Transduction of DNA information through water and electromagnetic waves. Electromagn Biol Med 34: 106-112. [Crossref]

55. Hecht L (2011) LucMontagnier's revolution in biology: New evidence for a nonparticle view of life. 21st Century Science \& Technology. Winter 2010/2011:6-11.

56. Klein SD, Wurtenberger S, Wolf U, Baumgartner S, Tournier A (2018) Physicochemical investigation of homeopathic preparations: A systematic review and bibliometric analysis-Part 1. J Altern Complement Med 24: 409-421. [Crossref]

57. Bellavite P, Marzotto M, Olloso D, Moratti E, Conforti A (2014b) High-dilution effects revisited. 2. Pharmacodynamic mechanisms. Homeopathy 103: 22-42. [Crossref]

58. Rattan SI, Deva T (2010) Testing the hermetic nature of homeopathic interventions through stress response pathways. Human Exp Toxicol 29: 551-554. [Crossref]

59. Bell IR, Schwartz GE (2013) Adaptive network nanomedicine: an integrated model for homeopathic medicine. Front Biosci (Schol Ed) 5: 685-708. [Crossref]

60. Hammerschlag R, Levin M, McCraty R, Bat N, Ives JA, et al. (2015) Biofield Physiology: A Framework for an Emerging Discipline. Glob Adv Health Med 4: 35-41. [Crossref]
61. Jain S, Hammerschlag R, Mills P, Cohen L, Krieger R, et al. (2015) Clinical studies of biofield therapies: summary, methodological challenges, and recommendations. Global Adv Health Med 4(suppl): 58-66. [Crossref]

62. Kafatos MC, Chevalier G, Chopra D, Hubacher J, Kak S, et al. (2015). Biofield science:current physics perspectives. Global Adv health Med 4(suppl): 25-34. [Crossref]

63. Muehsam D, Chevalier G, Barsotti T, Gurfein BT (2015) An Overview of Biofield Devices. Glob Adv Health Med 4: 42-51. [Crossref]

64. Rubik B, Muehsam D, Hammerschlag R, Jain S (2015) Biofield Science and Healing: History, Terminology, and Concepts. Glob Adv Health Med 4: 8-14. [Crossref]

65. Rubik B (2002) The biofield hypothesis: its biophysical basis and role in medicine. $J$ Altern Complement Med 8: 703-717. [Crossref]

66. Lenger K, Bajpal RP, Spielmann M (2014) Identification of unknown homeopathic remedies by delayed luminescence. Cell Biochem Biophys 68: 321-334. [Crossref]

67. Lenger K (2008) A new biochemical model of homeopathic efficacy in patients with chronic diseases. Subtle Energies \& Energy Medicine 19: 9-41

68. Marino R (2008) Homeopathy and collective health: The case of Dengue epidemics. Int $J$ High Dilution Res 7: 179-185.

69. Bellavite P, Conforti A, Piasere V, Ortolani R (2005) Immunology and homeopathy. 1 Historical background. Evid Based Complement Alternat Med 2: 441-452. [Crossref]

70. Hahnemann S (2005) The cure and prevention of scarlet fever. Lesser Writings. Jain Publishers. New Delhi, India.

71. Golden I (2012a) The complete practitioner's manual of homoeoprophylaxis. Gisborne, Victoria: Isaac Golden Publications.

72. Aparecida de Souza Nunes L (2008) Contribution of homeopathy to the control of an outbreak of dengue in Macae, Rio de Janeiro. Int J High Dilution Res 7: 186-192.

73. Bracho G, Golden I (2016) A brief history of homeoprophylaxis in Cuba, 2004-2014 Homoeopathic Links 29: 128-134.

74. Mroninski CRL, Adrian EJ, Mattos G (2001) Meningococcinum: Its protective effect against meningococcal disease. Homoeopathic Links 14: 230-234.

75. Castro D, Nogueira GG (1975) Use of the nosode Meningococcinum as a preventative against meningitis. J Am Inst Homeopath 68: 211-219.

76. Gadugu S, Nyapit SR (2013) An observational study on the efficacy of B.C.T. homoeopathic medicines in the prevention of Japanese Encephalitis in the state of Andhra Pradesh, India. Department of AYUSH, Ministry of Health, Government of India.

77. Golden I (in press) Large homoeoprophylaxis: brief and long-term interventions. $\mathrm{Am}$ $J$ Homeopath Med (Accepted for publication 27/1/2019. Due for publication March 2019).

78. Golden I, Bracho G (2014) A reevaluation of the effectiveness of homoeoprophylaxis against Leptospirosis in Cuba in 2007 and 2008. J Evid Based Complementary Altern Med 19: 155-160. [Crossref]

79. Bracho G, VarelaE,FernándezR, OrdazB, Marzoa N, et al. (2010)Large-scale application of highly-diluted bacteria for Leptospirosis epidemic control. Homeopathy 99: 156166. [Crossref]

80. Roninger H, Jacobs J (2010) Prophylaxis against Leptospirosis using a nosode: can lis large cohort study serve as a model for future replications. Homeopathy 99: 153-155. [Crossref]

81. Marino R (2008) Homeopathy and collective health: The case of dengue epidemics IJHDR 7: 179-185.

82. Sheffield F (2014) Homeoprophylaxis: Human records, studies and trials. National Center for Homeopathy [online] Available at: https://www.homeopathycenter.org/ homeoprophylaxis-human-records-studies-and-trials. [Accessed 2/12/19].

83. The Hindu (2016) Keep Dengue at bay with homoeopathy. [online] Available at: https:// www.thehindu.com/news/cities/Madurai/keep-dengue-at-bay-with-homoeopathy/ article3531685.ece. [Accessed 9/6/18].

84. Golden I (2012b) The complete practitioner's manual of homoeoprophylaxis. Gisborne, Victoria: Isaac Golden Pulications.

85. Golden I (2004a) A new program of long-term homoeoprophylaxis. Similia 16: 36-41.

86. Golden I (2004b) The potential value of homoeoprophylaxis in the long-term prevention of infectious diseases, and the maintenance of general health in recipients. [online] Available at: https://immunizationalternatives.com/wp-content/uploads/2015/04/HP Isaac_Golden_thesis_homeoprophylaxis.pdf. [Accessed 2/12/19]. 
87. Golden I (2004c) The safety of long-term homoeoprophylaxis-Research findings. Homeopathic Links 17: 261-263.

88. Danno K, Cognet-Dementhon B, Thevenard G, Duru G, Allaert FA, et al. (2013) Effectiveness of homeopathic medicine associated with allopathic medicine in the outpatient management of influenza-like illnesses or ear, nose, and throat disorders by pharmacists. J Manag Care Pharm 19: 631-641. [Crossref]

89. Mathie RT, Frye J, Fisher P (2015) Homeopathic Oscillococcinum for preventing and treating influenza and influenza-like illness. Cochrane Database Syst Rev 1:CD01957. [Crossref]

90. Haidvogl M, Riley DS, Heger M, Brien S, Jong M, et al. (2007) Homeopathic and conventional treatment for acute respiratory and ear complaints: a comparative study on outcome in the primary care setting. BMC Complement Altern Med 7: 1-11. [Crossref]

91. Riley D, Fischer M, Singh B, Haldvogl N, Heger M (2001) Homeopathy and conventional medicine: an outcomes study comparing effectiveness in a primary care setting. J Altern Complement Med 7: 149-159. [Crossref]
92. Siqueira CM, Homsani F, da Veiga VF, Lyrio C, Mattos H, et al. (2016) Homeopathic medicines for prevention of influenza and acute respiratory tract infections in children: blind, randomized, placebo-controlled clinical trial. Homeopathy 105: 71-77. [Crossref]

93. Marinone C, Bastard M, Bonnet PA, Gentile G, Casanova L (2017) Effectiveness of preventive treatment by Influenzinum in the winter period against the onset of influenza-like illnesses. Therapie 72: 465-474. [Crossref]

94. Golden I, van Nijnatten W, Hasselaar G (2016) A pilot study into the comparative effectiveness and safety in the elderly of a homeopathic flu prophylaxis and the regular flu vaccination in the Netherlands. Homeopathic Links 29: 120-126.

95. Frost C (2004) A double blind study on the comparative efficacy of influenza vaccination and influenzinum $7 \mathrm{CH}$. Faculty of Health Sciences, Technikon Wilwatersrand. Available at: https://scholar.google.com/scholar?hl=en\&as sdt=0\%2C5\&q=Frost $+\mathrm{C}$ $+\% 282004 \% 29+\mathrm{A}+$ double + blind + study + on + the + comparative + efficacy + of + influenza + vaccination + and + influenzinum $+7+\mathrm{CH} .+$ Faculty + of + Health + Sciences $\% 2 \mathrm{C}+$ Technik on+Witwatersrand.\&btnG $=$. [Accessed 2/12/19].

96. Bracho G, Golden I (2016) A brief history of homeoprophylaxis in Cuba, 2004-2014. Homeopathic Links 29: 128-134.

Copyright: (C2019 Buehning L. This is an open-access article distributed under the terms of the Creative Commons Attribution License, which permits unrestricted use, distribution, and reproduction in any medium, provided the original author and source are credited. 